\title{
DIREITO ECONÔMICO CONSTITUCIONAL: ANÁLISE COMPARADA DAS ORDENS ECONÔMICAS ESTATAIS BRASILEIRA E ESPANHOLA
}

\author{
Francieli Puntel Raminelli ${ }^{1}$
}

\section{RESUMO}

O objetivo deste artigo é apresentar algumas construções que resultaram na ordem econômica brasileira vigente hoje, bem como realizar uma comparação entre esta e sua equivalente na Espanha, por meio da comparação entre as Constituições de cada país. Busca-se responder a seguinte questão: em se aproximam e se distanciam as previsões constitucionais da ordem econômica brasileira e espanhola? Aplicam-se os métodos de abordagem dedutiva e de procedimento comparado, com técnica de pesquisa documental e bibliográfica. Conclui-se que as duas ordens econômicas constitucionais possuem inúmeras similitudes, devido ao traço fundamental que compartilham: a busca pela proteção do interesse público.

Palavras-Chave: Brasil. Constituição Econômica. Direito Econômico. Espanha. Ordem Econômica.

\section{CONSTITUTIONAL ECONOMIC LAW: COMPARED ANALYSIS OF BRAZILIAN AND SPANISH STATE ECONOMIC ORDERS}

\begin{abstract}
The purpose of this article is to present some constructions that resulted in the Brazilian economic order today, as well as to carry out a comparison between this and its equivalent in Spain, through the comparison between the constitutions of each country. We seek to answer the following question: in which are the constitutional predictions of the Brazilian and Spanish economic order approaching and distancing? The methods of deductive approach and comparative procedure are applied, with documentary and bibliographic research technique. It is concluded that the two constitutional economic orders have numerous similarities, due to the fundamental trait they share: the search for the protection of the public interest.
\end{abstract}

Keywords: Brazil. Economic Constitution. Economic Law. Economic Order. Spain.

\section{INTRODUÇÃO}

A compreensão da relação entre direito e economia envolve, além destas duas disciplinas, que por si já são bastante vastas, fatores como o poder político, a atuação do Estado e da sociedade, entre outros elementos que podem influenciar na forma como um

\footnotetext{
${ }^{1}$ Doutora em Direito Universidade Federal do Rio Grande do Sul (UFRGS) e pela Universidade de Sevilha (Espanha). E-mail: francieli.raminelli@gmail.com.
} 
determina e afeta o outro. O estudo de temas econômicos, assim, requer um amplo olhar sob diversos componentes do contexto em que se insere.

Por este motivo, o objetivo principal deste artigo é apresentar algumas construções que resultaram na ordem econômica brasileira vigente hoje, bem como, em um segundo momento, realizar uma comparação entre esta e sua equivalente na Espanha, por meio de uma análise comparativa entre alguns pontos das constituições de cada país. Busca-se, com isto, responder a seguinte questão: quais são os pontos de aproximação entra as previsões constitucionais das ordens econômicas brasileira e espanhola?

Não é intuito desta pesquisa analisar minuciosamente os artigos constitucionais de cada Estado, mas trazer uma comparação geral dos princípios e valores com os quais cada um se norteia, realizando um paralelo entre estas duas constituições que fixam seus Estados como Democráticos de Direito.

O método de abordagem aplicado neste artigo é o dedutivo, sendo o comparado o método de procedimento. Como técnica de pesquisa, utilizou-se de duas: documental e bibliográfica. O presente trabalho está dividido em dois capítulos: o primeiro, que abordará conceitos iniciais acerca de direito econômico, bem como a construção histórica do conceito e do papel do Estado em relação a atividade econômica; e o segundo, que trará uma comparação entre a ordem econômica brasileira e a ordem econômica espanhola, buscando realizar um panorama de pontos gerais destes dois ordenamentos.

A seguir, portanto, tratar-se-á da complexa relação entre economia, direito, sociedade, poder e capitalismo.

\section{DIREITO E ECONOMIA: BREVES APUNTAMENTOS}

A palavra "economia" tem sua origem de duas palavras gregas, "oikos", que significa casa, e "nomos", que se traduz como regras. Assim, da origem semântica do termo, tem-se que economia é a gestão ou a organização da casa, que pode ser entendida tanto no sentido de residência do indivíduo como no de sua cidade ou ambiente em que reside. Por existirem diferenças entre estes dois núcleos, a economia ainda pode subdividir-se em micro e macroeconomia, sendo a primeira aquela que se refere a questões particulares, de indivíduos e de empresas, e a segunda a que diz respeito a questões globais (CAMARGO, 2012). 
De acordo com o economista liberal David Friedman, a relação entre economia e direito pode ser explicada por um simples exemplo: um bêbado, quando perde sua carteira na rua, procura-a sempre sob o facho de luz do poste, ignorando a escuridão de toda a área iluminada; neste exemplo, o direito seria a escuridão, com seu vasto campo de valores subjetivos e a economia, o facho de luz. Por certo, este pensamento, oriundo de um pensador filiado a Escola de Chicago $^{2}$ já demonstra que, para alguns, direito e economia possuem uma relação, no mínimo, complexa.

Definir a relação entre economia e direito nem sempre é uma tarefa fácil; existe uma interdependência, uma impossibilidade de desvinculação de uma e de outra. O direito responde à economia e vice-versa, não sendo possível negar-se essa influência mútua. No entanto, embora a juridicidade não possa deixar de sofrer influências daquela, possui “intencionalidade própria que não se pode deixar de condicionar pela estrutura da economia" (BARBOSA, 2014, p. 636). Neste sentido, o direito possui o dever de ser o norte que determina de que maneira as atividades econômicas devem se dar, com respeito aos valores e princípios resguardados pelo ordenamento que representam.

Por este motivo, para alguns, a economia tem uma dependência do direito, uma vez que "o funcionamento harmonioso de um determinado sistema econômico requer um certo mínimo de regras de direito que assegurem a apropriação e o uso dos factores de produção, dos produtos e dos serviços" (VAZ, 1998, p. 15). Assim, para que se tenha economia, será necessária uma ordem, uma determinação prévia que mantenha sua coesão e que poderá ser suprida pelo direito. Sendo uma das funções do direito a de manter a sociedade organizada (PÉREZ-LUÑO, 2014), não surpreende que seja usado para este fim em outros tipos de sistemas. A economia, portanto, necessita da regulamentação ofertada pelo direito.

O estudo da economia sob o viés do direito, chamado direito econômico, também não possui uma natureza bem definida, sendo entendido por alguns como disciplina integrada aos direitos públicos e privados (ordem econômica se vincula ao direito constitucional, intervenção do Estado na economia é tema de direito administrativo, regulamentação de empresas tema de direito empresarial, etc). Este posicionamento defende que o direito econômico é "um mosaico incoerente de institutos jurídicos que, num dado momento, nos aparecem nos intervalos das disciplinas tradicionais" (VAZ, 1998, p. 15). Sendo assim, este

\footnotetext{
${ }^{2}$ Em síntese, a Escola de Chicago é uma escola de pensamento econômico que defende o mercado livre e que foi disseminada por alguns professores da Universidade de Chicago.
} 
primeiro posicionamento dissipa o direito econômico em diversas matérias de direito, uma vez que, por certo, todas terão relação entre si e poderão ser supridas dentro de suas individualidades.

Ademais, para aqueles que não o entendem o Direito Econômico como ramo autônomo, ele pode ser visto como "uma ordem jurídica que corresponde às normas e necessidades de uma civilização ainda em vias de formação" (VAZ, 1998, p. 19), ou seja, um novo tipo de direito, ainda em construção, mas que está consubstanciado nas matérias tracionais do direito. Para esta linha de pensamento pode-se perfeitamente encaixar dentro do direto, ainda que este não esteja bem definido, as necessidades de um estudo jurídico voltado para a economia, já que essa, por sua vez, possui inúmeros fatores em construção e que podem variar, o que se justifica por ser um "novo direito".

Para os que defendem o direito econômico como um ramo autônomo, o subdividem em conceitos restritos e amplos. Como restritos, tem-se o direito econômico como noção de direito público, que possui uma autonomia científica e se volta para questões de intervenção do Estado na atividade econômica; e o direito econômico como direito dos negócios, que seria o estudo das atividades da empresa, em uma visão microeconômica (excluindo a macroeconomia e servindo mais como resposta a questões eminentemente práticas de empresários e seus quadros).

Já o entendimento amplo importa um entendimento de que o direito econômico é uma "disciplina jurídica de todas as relações sociais com conteúdo econômico" (VAZ, 1998, p. 23). Para não se ter uma dispersão em razão deste alargamento, é necessário, no entanto, determinar critérios que definam a extensão da matéria. Neste sentido, para esta compreensão, o direito econômico é autônomo, mas deve ter seu objeto bem identificado, sob pena de ser confundido com um conglomerado de matérias de direito.

De todos os modos, não é possível compreender o direito dissociado da economia, e muito menos, ambos dissociados da sociedade. Não é segredo que os três possuem conexões muito estreitas, determinando evoluções e modificações uns aos outros. Isto fica muito claro por meio da análise da evolução do poder. Se inicialmente todas as civilizações eram fundamentadas na religião, o surgimento de uma nova cultura, na baixa idade média, baseada no interesse econômico próprio, criou a primeira civilização mundial adaptável a todas as religiões: o capitalismo (COMPARATO, 2014, p. 1115). 
De seus primeiros dias até hoje, o capitalismo modificou-se em alguns aspectos, crescendo imensuravelmente e gerando imensas desigualdades em razão da busca incessante pelos interesses particulares de cada indivíduo. Estes desequilíbrios sociais resultantes, no entanto, nem sempre foram facilmente perceptíveis ou um consenso, pois, por exemplo, defendia Adam Smith que a busca de todos por seus interesses próprios, suas paixões, acabaria por gerar o bem comum. Era a chamada mão invisível do mercado, pela qual, ao realizar os seus interesses e contratar com outra pessoa de acordo com interesses comuns, todos chegariam ao seu próprio bem, agindo individualmente, mas com resultados satisfatórios na totalidade (SMITH, 1999).

Os modelos de Estado, de certa forma, também evoluíram levando em consideração a eterna questão dos interesses privados versus o interesse comum. O chamado Estado Absolutista, caracterizado pelos excessos do clero e da nobreza, que "fomentou o advento de um poder burguês muito potente, configurado no capital móvel financeiro, comercial e industrial" (SOARES, 2008, p. 79), foi substituído pelo Estado Liberal de Direito. Este possuía o fim precípuo de "dar aqueles que controlavam a economia (os burgueses) ampla liberdade de exercerem suas atividades, sem estarem ameaçados por qualquer outro poder" (ARAÚJO, 1997, p. 17) e tinha como característica ser mínimo, respeitando os direitos individuais e não intervindo na economia, a qual era considerada auto regulável.

O estado liberal possuía estreita ligação com a lei, sendo que a expressão Estado de Direito (Rechtsstaat), cunhada por juristas alemães em fins do século XIX, "designa a organização política na qual todo o poder, público ou privado, é limitado e controlado por normas jurídicas gerais, não sendo submetido à vontade ou ao interesse particular dos que detêm o poder" (COMPARATO, 2014, p. 1131).

Com o Estado Liberal, surge uma postura ultra individualista, uma concepção individualista e formal da liberdade, na qual há a liberdade e não o poder de ser livre; igualmente, forma-se o proletariado, em consequência da Revolução Industrial (STRECK e MORAIS, 2006, p. 62). Por estas consequências, o conceito limitador do Estado de garantidor da paz e da segurança é modificado, assumindo também outros papéis, como o de prestador de serviços públicos, ou, até mesmo como interventor socioeconômico. O Estado passa a intervir em espaços até então próprios da iniciativa privada desaparecendo, assim, a figura do Estado Mínimo. Tem-se, agora, o Estado Social de Direito, que se apresenta como "um tipo 
de Estado que tende a criar uma situação de bem-estar geral que garanta o desenvolvimento da pessoa humana" (STRECK e MORAIS, 2006, p. 62).

O desequilíbrio social existente entre os indivíduos nas sociedades era gritante, uma vez que o chamado estado social, apesar das boas intenções, não conseguiu atingir o bemestar geral. Em razão disso, defende-se a constituição do Estado Democrático de Direito, o qual visava a modificação efetiva do status quo, por meio de medidas que tivessem como escopo primordial o ser humano. Aqui, o Estado é apenas uma ferramenta, um meio utilizado para atingir os fins de dignidade mínima para todo os seres humanos.

Este resgate histórico é importante uma vez que a questão de dominação do poder, em todos os períodos de evolução, sempre remete aos interesses de cada indivíduo, não sendo diferente do que existe nos dias atuais. De uma breve análise, observa-se que o poder passou do monarca soberano até os burgueses e, apesar de diversas tentativas de melhor distribuição, jamais saiu das mãos desses. Assim, ainda no Estado Democrático de Direito, que busca alcançar ao menos o mínimo de dignidade para cada ser humano, existem questões que ultrapassam o interesse público e se voltam aos direitos particulares.

De fato, a compreensão do que seria este interesse público pode variar. Nos dias atuais, no entanto, pode ser compreendido como aquele que busca a defesa do meio ambiente, dos consumidores e do acesso aos serviços públicos universais, de qualidade e seguros, com continuidade e acessibilidade à toda população e sem exclusão em razão de questões econômicas (preço razoável) (AVELÃS NUNES, 2007, p. 13).

Da mesma forma que a evolução do conceito de Estado ocorreu, também a maneira como este se relacionou com o mercado foi diversa. Se no Estado absoluto havia um controle total por parte do rei, durante o estado liberal, em razão dos interesses burgueses, o que se teve foi um estado mínimo, que deixava o mercado autorregular-se. Com o Estado Social, no entanto, tem-se um estado mais interventor, que toma para si algumas responsabilidades e age com mais intensidade dentro da economia.

Este estado foi chamado por muitos de Estado Empresa, e consiste na ampliação do aparelho do estado, buscando atender as necessidades advindas das transformações oriundas do processo de desenvolvimento. Criticado principalmente por aqueles que são contrários a um estado que exerça um papel ativo dentro do mercado, para outros, estas ações tomadas não significam "nem resultado inexorável de determinações estruturais irresistíveis, nem produto da ideologia da afirmação autoritária e voluntarista de um projeto estatista de elites bem 
situadas na estrutura de poder. São produto de respostas políticas a problemas estruturais" (ABRANCHEZ, 1979, p. 103).

A compreensão de que o Estado deve intervir na economia para que esta se mantenha equilibrada embasa-se nas denominadas teorias Keynesianas. Este conjunto de teorias foi criado após os estudos iniciais de John Maynard Keynes, que "evidenciou que a intervenção do Estado era necessária dada a inerente instabilidade endógena da economia, bastando pensar nas forças de crescimento e desenvolvimento que, necessariamente, levam ao desequilíbrio" (DONÁRIO e SANTOS, 2016, p. 10). Ele é intensamente combatido pela corrente teórica neoliberal, que defende o esvaziamento das funções do Estado fundamentado nas teorias keysenianas e aponta para soluções mais radicais, como a neutralidade da política e economia (AVELÃS NUNES, 2007, p. 9-12).

No entanto, aos que defendem a intervenção, o argumento que prevalece é o de que o Estado empresa busca os fins públicos e não competir com o setor privado, pelo contrário: o Estado que atua na economia apoia os interesses privados. Em resumo "que seja capitalista, sem ser privada; que se comporte empresarialmente, para realizar fins públicos, isto é, macroeconômicos" (ABRANCHEZ, 1979, p. 104).

Consoante aponta Abranches (1979, p. 103), o Estado como empresa gera a expectativa de que suas atividades sejam capazes de abranger tanto as virtudes da gerência privada e sua característica empresarial como aquelas virtudes tradicionais pertencentes à administração pública, principalmente a visão global e a orientação ao cumprimento do interesse geral. No entanto, por diversas razões, muitas vezes a ineficiência do Estado no exercício destas atividades gera desconforto e insatisfação, o que auxiliou o fortalecimento do pensamento de que uma menor intervenção estatal e um livre mercado são o melhor caminho a ser seguido. A este pensamento seguiu uma tendência as privatizações de empresas e serviços públicos e uma redução na sua atividade interventiva.

De acordo com Avelãs Nunes, este foi um dos aspectos da "contrarreforma" que culminou na alteração do papel do Estado no pertinente a economia. Esta "onda de privatizações de empresas públicas, mesmo na área dos serviços públicos, na qual o estado detinha, em toda a Europa, há mais de dois séculos, um papel decisivo" foi apenas a consequência da forte rejeição que este sofreu como operador e interventor da economia. Seu papel de direção e planificação econômicas foi anulado, assim como seu viés empresário e de prestador de serviços (AVELÃS NUNES, 2007, p. 10). 
Atualmente, em razão das modificações do papel estatal, utilizam-se os termos estado garantidor ou regulador. De acordo com Canotilho (1998, p. 571), este Estado marca uma "mudança estrutural no cumprimento das tarefas públicas por parte do Estado", uma vez que também se refere às denominadas "reformas da administração no âmbito dos serviços públicos de interesse geral". Em suma "se trata de uma estratégia destinada a alicerçar um processo colectivo de aprendizagem dos poderes públicos no contexto mais vasto da liberação e da globalização" (CANOTILHO, 1998, p. 572).

Esta nova "feição capitalista" surge a partir dos anos 1980 e não objetiva deixar totalmente de lado a face intervencionista, mas "condicionar ou balizar a atuação dos agentes econômicos, em nome da necessidade de salvaguardar o interesse público" (AVELÃS NUNES, 2007, p. 12). Busca agir como um estado liberal que, no entanto, garante o funcionamento da economia de mercado com uma verdadeira livre concorrência.

Este entendimento de que o estado não presta um serviço eficiente o suficiente, e seu consequente afastamento das atividades econômicas possui também motivações capitalistas. Ocorre que o mercado de serviços é bastante rentável, vale milhões, e, por isto, é de interesse de alguns que seja privatizado. Isto se motiva no fato de que "o progresso científico e tecnológico, o welfare state e a melhoria das condições de vida transformaram em necessidades básicas das pessoas o acesso a determinados bens e serviços" (AVELÃS NUNES, 2007, p. 11).

Assim, serviços relacionados a saúde, segurança, educação, água, luz, saneamento, entre outros, sendo serviços de necessidade básica, acabam gerando a possibilidade de um lucro bastante desejável. A questão, no entanto, é que no momento em que se privatiza certas prestações de serviço, perde-se o verdadeiro intuito de interesse público e o que se busca é a vantagem econômica. Por isto, em razão de privatizações, por exemplo, já não se pode garantir um preço acessível a todos ou, ao menos, o acesso a todos os indivíduos a estes serviços básicos. Tem-se uma modificação do público para o privado, o que acarreta, também, na modificação dos objetivos almejados.

Por este e outros motivos, Canotilho elenca uma série de dúvidas ou ambiguidades acerca do Estado Garantidor. Questiona o mestre português, primeiramente, o que significa "garantia" neste contexto, e, se for no intuito de proteger, quem será o garantido pelo Estado. Trata-se, segundo ele, de uma mudança do paradigma do estado produtor para o estado 
regulador, aquele que apenas se compromete com a realização dos serviços por meio de outros instrumentos, em grande parte privados.

Em segundo lugar, observa que o Estado Garantidor possui uma alma de "Estado Social", mas seu corpo é de empresa, ou seja, possui o intuito proteger os interesses públicos, no entanto, delega a outros que realizem os serviços, apenas acompanhando o que é entregue. Neste ponto, ao mesmo tempo em que é apenas garantidor, também deve ser ativador, pois "deve, ao mesmo tempo, apoiar activamente a economia e a saúde ecónomica das empresas encarregadas de produzir os serviços e os bens indispensáveis à efectivação da socialidade" (CANOTILHO, 2008, p. 572). Em terceiro lugar, relativo a esta questão dos dois vieses do Estado, aponta Canotilho que o "charme" da relação está em fazer parecer que isto será benéfico para ambas as partes, tanto para o interesse público, que será mantido, quanto para os interesses privados, que lucraram com esta modificação.

Esta possibilidade de relação win-win relaciona-se ao quarto ponto levantado, uma vez que é impossível que exista a garantia do público e do privado, ao mesmo tempo: "a prova disto é dada pelos chamados 'investimentos encalhados' e pelos 'custos de transição' para a privatização que não raro justificam repercussões dos custos para a privatização dos serviços" (CANOTILHO, 2008, p. 574). Ou seja, a própria privatização, para ocorrer, muitas vezes gera um investimento que será arcado pela própria sociedade, sendo muitas vezes não um verdadeiro investimento, mas um custo, vez que nem sempre existe retorno para seus “investidores" (cidadãos).

O quinto ponto acerca do termo "Estado Garantidor" versa sobre a responsabilidade, que também deveria ser expressa. Qualquer seja o nome utilizado, garantidor, ativador ou regulador, haverá a responsabilidade de manter-se o interesse público, e esta caberá ao Estado. Canotilho (2008, p. 574) faz uma importante reflexão: “O problema não é o de reiterar, de forma saturada e improdutiva, o slogan de mais ou menos Estado, mas o de legitimar novas formas e uma qualidade de actividade do Estado". Assim, compreende-se que ainda que o Estado não intervenha diretamente na economia, sendo regulador e não empresa, deverá ter como atividade principal a manutenção de uma economia que respeite os valores determinados pelo ordenamento, encontrando melhores e novos caminhos para garanti-los.

Observa-se, portanto, que a questão relativa aos interesses envolvidos nas atividades econômicas sempre serão chave para a determinação de um ou outro modelo econômico. Se o interesse público efetivamente é garantido, o interesse privado será afetado, principalmente 
porque a ideia do lucro é central no capitalismo, mas não o deve ser quando se trata de questões de necessidade básica, como os serviços públicos já mencionados. O ser humano tem direito a condições mínimas de dignidade e é isto que busca o Estado Democrático de Direito, último estágio da evolução dos modelos de Estado.

A crítica realizada ao modelo de estado "garantidor" ou "regulador" baseia-se justamente no fato de que este modelo se mostra insustentável, com inúmeras ambiguidades a serem superadas. Por certo o interesse particular pode e deve existir, e cada indivíduo é livre para lucrar dentro de suas atividades. O que não pode ocorrer, no entanto, é que se aproveite de situações que têm relevância e interesse social para obter-se lucros para o mercado privado, mantendo a riqueza de alguns as custas da privação de direitos de outros. A lógica do mercado é uma: lucro. A não intervenção do Estado em determinados setores possui um único resultado, e ele não será a proteção dos indivíduos e de seus direitos fundamentais.

Demonstra-se necessário a regulação do mercado pelo Estado, principalmente quando se tratar de interesses públicos versus os privados. Após tantas investidas contra o poder estatal e seu nível de intervenção, com o consequente "sucateamento" das estruturas estatais, a regulamentação é o mínimo que deve ser garantido, uma vez que para muitos, "não significa mais do que a tentativa de tapar o sol com a peneira. A mão invisível do mercado deu o lugar à mão visível dos grandes conglomerados transnacionais. São eles que mandam no mercado" (AVELÃS NUNES, 2007, p. 16).

Portanto, a construção de modelos estatais com maiores ou menores poderes de intervenção econômica são fruto da influência que o capitalismo, em seu ímpeto de lucro, gera dentro da atividade econômica. Os interesses privados sempre terão uma força para movimentar e modificar tudo aquilo que for necessário, uma vez que, guiado por suas paixões o ser humano alcança tudo o que deseja. O mesmo não pode ser dito acerca de interesses da coletividade, que, infelizmente, acabam normalmente cedendo em razão do jogo de influências e poderes envolvidos em todo o contexto.

No intuito de garantir, ao menos, o seu poder e dever de regulação, inúmeros Estados possuem previsões constitucionais acerca de seu papel perante a atividade econômica exercida sob sua tutela e em seu território. Brasil e Espanha são exemplos de países que possuem essa determinação constitucional, que serão analisadas no tópico a seguir. 


\section{A ORDEM ECONÔMICA NA CONSTITUIÇÃO ESPANHOLA DE 1978} E NA CONSTITIÇÃO FEDERAL BRASILEIRA DE 1988: ANÁLISE COMPARATIVA

Brasil $^{3}$ e Espanha ${ }^{4}$ são dois países constituídos como Estado Democrático de Direito $^{5}$, o que se depreende no primeiro artigo de cada uma de suas Constituições. Como já analisado anteriormente, este modelo de Estado busca a dignidade do ser humano como fim último, no intuito de proteção dos direitos humanos e garantia de uma mínima qualidade de vida para seus cidadãos.

Em relação a suas regulamentações no pertinente as atividades econômicas, cada um dos Estados possuem determinações expressas em suas constituições. No Brasil, o título VII prevê "Da Ordem Econômica e Financeira", e possui quatro capítulos: dos princípios gerais da atividade econômica; da política urbana; da política agrícola e fundiária e da reforma agrária; e do sistema financeiro nacional (BRASIL, 1988). Ao todo, são vinte e dois artigos que regulamentam questões econômicas, sendo que ao longo da Constituição outros artigos também fazem referência temas correlatos. Para esta análise, tratar-se-á, principalmente, do primeiro capítulo, que traz ditames gerais da atividade econômica no Brasil.

Na Constituição Espanhola, que por sua vez é bastante mais sucinta, encontrar-se-á o “Título VII. Economía y Hacienda”, com o qual, em nove artigos serão regulamentadas as principais temáticas econômicas do país. Por certo também nesta Constituição outros artigos fazem referência a temas vinculados a atividade econômica. Quando relevantes, estes artigos, embora em outros trechos, serão indicados.

É importante ressaltar que, embora se tratem de questões pontuais relacionadas as ordens econômicas de cada Constituição, é impossível não realizar uma análise contextualizada da Constituição. Não se pode analisar a regulamentação econômica

\footnotetext{
${ }^{3}$ Art. $1^{\circ}$ A República Federativa do Brasil, formada pela união indissolúvel dos Estados e Municípios e do Distrito Federal, constitui-se em Estado Democrático de Direito e tem como fundamentos [...] (BRASIL, 1988) ${ }^{4}$ Artículo 1. España se constituye en un Estado social y democrático de Derecho, que propugna como valores superiores de su ordenamiento jurídico la libertad, la justicia, la igualdad y el pluralismo político (ESPAÑA, 1978).

5 "O comportamento do legislador constituinte, definindo para o País um 'Estado Democrático de Direito' (art. $1^{\circ}$ ), evitando a expressão 'Estado de Direito', de sabor liberal, e aproximando-se do discurso da Carta Portuguesa de 1975 - embora não avançando ao ponto da Espanhola, de 1978, que consagra o 'Estado Social e Democrático de Direito' (art. $1^{\circ}$ ) -já autoriza-nos, salvo melhor juízo, a detectar na Carta de 1988 os elementos de uma 'economia de mercado' distanciada do modelo liberal puro e ajustada à ideologia neoliberal, sendo este o único prisma capaz de permitir a sua análise correta" (GRAU, 2010, p. 187).
} 
constitucional de um ordenamento sem considerar princípios e regras que transpassam a "lei fundamental" daquele. O direito econômico, assim, seja considerado autônomo ou não, não pode prescindir do direito constitucional para ser interpretado.

De todas as formas, as regulamentações e determinações relativas as atividades econômicas, quando inseridas na Constituição de algum Estado, são englobadas pela terminologia "constituição econômica", que foi definida pelo Tribunal Constitucional Espanhol no seguinte trecho:

Na Constituição Espanhola de 1978, diferentemente do que costumava acontecer com as Constituições liberais do século XIX e semelhante ao que acontece nas Constituições europeias mais recentes, existem várias regras destinadas a fornecer o arcabouço jurídico fundamental para a estrutura e funcionamento da atividade econômica; o conjunto de todos eles compõe o que é geralmente chamado de Constituição Econômica (livre tradução) [...] (ESPANÃ, 1982, livre tradução).

Em suma, a Constituição Espanhola, alinhada com o constitucionalismo europeu pós segunda guerra e a concepção de Estado Democrático de Direito, contém em seu texto abundantes referências a matérias e instituições econômicas enquanto participa da concepção, comum as sociedades modernas, de que a economia, por sua dimensão social, ostenta um protagonismo essencial para a convivência democrática e a configuração de uma ordem social justa.

Ademais, é possível apontar a existência de duas grandes áreas dentro da constituição econômica: a constituição econômica propriamente dita, dentro da Constituição e fora dela nos correspondentes quadros legislativos - e a definição das decisões fundamentais que afetam a vida econômica e social, isto é, as liberdades básicas de escolha profissional e atividade, gestão de mercado, concorrência, garantias de propriedade, etc., em um conceito já arraigado na ciência econômica chamada "ordem econômica". Esta segunda área afeta a "administração da economia", e traz as instituições e normas jurídicas que regulam legalmente as consequências da ordem econômica (ECHEVARRÍA, 1978, p. 9).

De fato, a ordem econômica na constituição é um elemento primordial e determinante do desenvolvimento da sociedade como comunidade e também de cada um dos indivíduos que a compõe. A escolha por determinada ordem econômica será chave para a vida de uma sociedade, em conjunto. É, portanto, uma decisão fundamental em que se deve estabelecer e regular o papel do Estado na economia, como se regulam direitos de propriedade 
deste, como funcionaram as liberdades profissionais e econômicas, etc. (ECHEVARRÍA, 1978, p. 9).

O conceito de "ordem econômica", para Eros Grau, constitui uma "parcela da ordem jurídica (mundo do dever-ser)", ou seja "o conjunto de normas que institucionaliza uma determinada ordem econômica (mundo do ser)" (GRAU, 2010, p. 70). Em outras palavras, são as regras que institucionalmente determinam o modo de produção econômica no Estado dos quais tratam.

Não obstante, dentro da ordem econômica não apenas deverão estar as normas, mas também o conjunto de valores que determinará o tipo de ordem que se estabelece. Por exemplo, devem existir previsões acerca da "intervenção do Estado na economia como uma das questões fundamentais que configuram o marco de liberdades para a atuação privada" (ECHEVARRÍA, 1978, p. 9). Os princípios constitucionais devem direcionar a construção da ordem econômica de um Estado.

No Brasil, o primeiro artigo dentro da ordem econômica constitucional é o art. 170, que elenca uma série de princípios guias para a determinação das atividades econômicas no país. O primeiro ponto a ser observado é que, já em seu caput, existe a previsão do respeito ao interesse público, uma vez que a ordem econômica se funda "na valorização do trabalho humano e na livre iniciativa, tem por fim assegurar a todos existência digna, conforme os ditames da justiça social" (BRASIL, 1988).

De acordo com Grau (GRAU, 2010, p. 70), a ordem econômica da Constituição Brasileira de 1988 aponta para um "regime de mercado organizado", que consiste naquele que sofre direcionamentos baseados no interesse público. O Brasil, então, elegeu o processo econômico de tipo liberal ${ }^{6}$, com a possiblidade de intervenção do Estado em situações pontuais de abusos e necessidade de garantia da livre concorrência.

O Estado tem como dever evitar a formação dos monopólios e abuso de poder que busque o aumento dos lucros de forma arbitrária - ainda que se permita e proteja a livre iniciativa. Resume Grau, com base em diversos doutrinadores, que o modelo brasileiro se ajusta ao neoliberal, repudiando o dirigismo, mas acolhendo o intervencionismo a favor do

\footnotetext{
${ }^{6}$ O Supremo Tribunal Federal (STF), na Ação Direta de Inconstitucionalidade $n^{\circ} 319$ entendeu que a Constituição Federal consagra um modelo social, uma vez que o art. 170 utiliza o termo "justiça social" e o artigo $1^{\circ}$, IV, o termo "valores sociais do trabalho e da livre iniciativa". Assim, o STF afirmou que o exercício de qualquer atividade econômica somente será legitimamente exercido se cumprida a sua finalidade social. É o posicionamento decorrente de interpretação sistemática da Constituição Federal (BRASIL, 1993).
} 
mercado, sendo considerada capitalista, mas admitindo a liberdade apenas quando realizada no interesse da justiça social (GRAU, 2010).

Entre os princípios previstos estão a soberania nacional, a propriedade privada, a função social da propriedade, a livre concorrência, a defesa do consumidor, a defesa do meio ambiente, a redução das desigualdades regionais e sociais, a busca do pleno emprego, o tratamento favorecido para as empresas de pequeno porte constituídas sob as leis brasileiras e que tenham sua sede e administração no País. Ademais, assegura-se "a todos o livre exercício de qualquer atividade econômica, independentemente de autorização de órgãos públicos, salvo nos casos previstos em lei” (BRASIL, 1988).

Todos estes princípios devem ser ponderados e compreendidos na globalidade do contexto econômico (GRAU, 2010, p. 196), o que não exclui, certamente, outros princípios consubstanciados na própria constituição. Desde seu caput, o art. 171 (BRASIL, 1988) deixa claro que o objetivo da regulação da atividade econômica tem por finalidade a garantia dos direitos mais básicos de cada indivíduo, o que, portanto, permite a compreensão de que, em caso de violação, a atividade econômica não será protegida pela constituição.

A previsão constitucional espanhola, por sua vez, embora não preveja princípios específicos em seus artigos da "ordem econômica", possui esta previsão no capítulo terceiro do Título I, em que trata dos "Principios rectores de la politica social y econômica" (ESPANÃ, 1978). Embora as normas não se contraponham, a explicação para a localização apartada em dois pontos diferentes ocorre com base no fato de que, enquanto o capítulo que versa sobre os direitos fundamentais trate de uma vertente subjetiva da perspectiva destes direitos, os artigos do capítulo específico sobre economia (128 a 132) marcam o conceito sob a perspectiva objetiva do Estado, de forma que servem aos fins deste último (FERNÁNDEZSANTA CRUZ, 2003).

Ademais, é salutar ressaltar que a Constituição espanhola não se constitui, neste ponto, em um código rígido, mas, assim como feito com outras matérias, se há optado por configurar um marco amplo e flexível, que parte de uma economia de mercado que pode ser considerada uma economia mista com preponderância pública até uma economia mista com preponderância privada, sempre dentro dos limites impostos pelos princípios e normas constitucionais (FERNÁNDEZ-SANTA CRUZ, 2003).

Sobre este ponto de "flexibilidade" possibilitada pela Constituição espanhola, Garcia (2003) faz referência acerca da função reguladora do Estado, já previamente abordada. 
Defende que é por meio da flexibilidade do princípio da legalidade, entendido como a supremacia da lei elaborada dentro dos ditames legais, que por diversas vezes o Estado espanhol deixa de intervir em situações que deveria.

Assim, embora existam transformações visíveis na atuação do Estado na economia, sustenta que estas não podem permitir um deslocamento dos princípios e regras constitucionais previsto pelo Estado Social e Democrático de Direito espanhol. Ainda que o Estado assuma novos papeis, como é o caso do Estado garantidor/regulador, é necessário que sejam articulados novos equilíbrios na articulação dos poderes, sendo os princípios de segurança jurídica e respeito à lei chamados a desempenharem um papel fundamental.

Ademais, em seu art. $128^{7}$, a Constituição espanhola prevê quatro importantes pontos definidores de sua política econômica: 1) a subordinação de toda a riqueza do país ao interesse geral; 2) o reconhecimento da iniciativa pública na atividade econômica; 3) a reserva ao setor público de recursos ou serviços essenciais; e 4) a intervenção pública de empresas.

O primeiro possui relação com a função social do direito e da propriedade privada, bem como da expropriação forçada, uma vez que ninguém pode ser privado de seus bens e direitos se não por causa justificada de utilidade pública ou interesse social ${ }^{8}$. Assim, embora seja protegido o direito individual, em qualquer situação que se evidencie o interesse público, este poderá ceder em razão do maior peso do interesse social.

No pertinente a iniciativa pública na atividade econômica, não significa a mesma iniciativa que é permitida para os privados. Somente haverá intervenção do Estado quando esta servir ao interesse geral, ou seja, é necessário encontrar uma justificativa que sustente esta decisão. Por certo, esta atuação deve estar de acordo com aquilo sempre requerido nas ações estatais: "servir com objetividade aos interesses gerais e atuar de acordo com os princípios da eficácia, hierarquia, descentralização, desconcentração e coordenação submetendo-se plenamente a lei e ao direito" (ESPAÑA, 1978) ${ }^{9}$.

\footnotetext{
${ }^{7}$ Articulo 128. Toda la riqueza del país en sus distintas formas y sea cual fuere su titularidad está subordinada al interés general. Se reconoce la iniciativa pública en la actividad económica. Mediante ley se podrá reservar al sector público recursos o servicios esenciales, especialmente en caso de monopolio y asimismo acordar la intervención de empresas cuando así lo exigiere el interés general (ESPAÑA, 1978).

${ }^{8}$ Artículo 33. Se reconoce el derecho a la propiedad privada y a la herencia. La función social de estos derechos delimitará su contenido, de acuerdo con las leyes. Nadie podrá ser privado de sus bienes y derechos sino por causa justificada de utilidad pública o interés social, mediante la correspondiente indemnización y de conformidad con lo dispuesto por las leyes (ESPAÑA, 1978).

9 “Artículo 103. 1. La Administración Pública sirve con objetividad los intereses generales y actúa de acuerdo con los principios de eficacia, jerarquía, descentralización, desconcentración y coordinación, con sometimiento pleno a la ley y al Derecho [...]”. (ESPAÑA, 1978).
} 
Quanto a reserva ao setor público de recursos ou serviços essenciais, dois pontos são relevantes para esclarecimento. Primeiro, o que se entende por serviços essenciais, que não possui unanimidade na doutrina, mas que podem ser definidos como "serviços indispensáveis para o funcionamento da sociedade" (FERNÁNDEZ-SANTA CRUZ, 2003), ou seja, serviços dos quais a coletividade necessita para existir. E segundo, o entendimento de que esta "reserva" não significa que os serviços somente poderão ser prestados pelo Estado, ou seja, poderão ser realizados pela iniciativa privada desde que exista um forte controle estatal, com exceção de serviços que por sua natureza configurariam monopólio e que, portanto, obrigatoriamente devem ser prestados diretamente pelo Estado.

Por fim, o último ponto, referente a intervenção pública de empresas, somente ocorrerá quando houver razões de interesse geral, permanecendo a titularidade das mesmas nas mãos de seus proprietários, mas com a gestão e atividade dirigidas por um órgão de natureza pública que participa da tomada de decisões ou substitua totalmente os órgãos normais de decisão (FERNÁNDEZ-SANTA CRUZ, 2003).

Na Constituição brasileira (BRASIL, 1988), estas questões estão espraiadas em vários artigos. Trata-se da propriedade privada e de função social como princípios no art. 170; a exploração da atividade econômica pelo Estado, que "só será permitida quando necessária aos imperativos da segurança nacional ou a relevante interesse coletivo, conforme definidos em lei" no art. 172; a prestação de serviços públicos, diretamente pelo Estado ou pelo setor privado, sempre por meio de licitação, no art. 175; e, por fim, no pertinente a intervenção de empresas, embora não exista um artigo específico na Constituição Brasileira, entende-se que, se houver relevante motivo de interesse público, em razão do contexto de princípios e fins sociais do Estado Democrático de Direito, é possível a intervenção estatal dentro dos limites impostos por lei.

Analisadas as características gerais das ordens econômicas brasileiras e espanhola, ainda que estas possuam características bastante diversas em sua formação (como, por exemplo, o fato da Espanha estar inserida no um bloco econômico europeu e ter regramentos internacionais que também regem sua economia), é visível que existem inúmeras similitudes em seus ordenamentos.

Estas, por certo, são frutos daquela que é o traço que desenha ambas as constituições econômicas desses países: a relevância e prioridade dada aos interesses públicos. 


\section{CONCLUSÃO}

O Direito econômico, seja considerado ramo autônomo ou não, vincula-se a diversas matérias de direito e, para além disso, questões econômicas e políticas de um Estado. Para aqueles que se definem como Estado Democrático de Direito, regulamentar e muitas vezes intervir na economia é tarefa essencial no intuito de se manter o escopo máximo de resguardo da dignidade da pessoa humana e seu mínimo existencial.

Muito se discute, no entanto, o papel que o Estado deve exercer junto à economia, se mais ou menos ativo e quando as intervenções seriam justificáveis. De uma análise dos períodos históricos, percebe-se que já existiram modelos Estatais com diferentes níveis de atividade, desde um estado absolutista, que dominava completamente a economia, até um Estado mínimo que permitia a auto-regulamentação do mercado, existindo entre estes extremos o Estado Empresa, que atua efetivamente nas atividades econômicas e o Estado Regulador ou Garantidor, que possui o foco na regulamentação para uma maior liberdade de mercado.

Não se pode definir um único modelo como o melhor, sendo necessária uma análise de acordo com o contexto de cada Estado. Além da análise de seu histórico, é necessário considerar sua construção social, as formas como os indivíduos que o compõem pensam e atuam e os valores que naquele país são defendidos. Desta maneira, a definição do tipo de atividade estatal virá definida pelas Constituições de cada país, falando-se de constituição econômica quando existirem regras gerais acerca da atividade econômica previstas na Lei Fundamental. Dentro da constituição econômica tem-se ainda a ordem econômica, que será o norte direcionador do mercado, seja ele privado ou mesmo público.

Da análise realizada nas Constituições Brasileira e Espanhola, tem-se uma aproximação nos princípios norteadores da atividade econômica. Enquanto no Brasil estes vem expressamente elencados no art. 170 da Constituição Federal de 1988, na Espanha eles aparecem de uma maneira subliminar, fazendo referência a determinações expressas previstas nos títulos específicos de direitos fundamentais do cidadão.

Este vínculo demonstra que para aquela ordem, a atividade econômica deve respeitar todos os limites impostos em razão dos direitos humanos mais básicos, como, por exemplo, o direito à saúde, à segurança, à educação, etc. Dessa forma, ainda que ao mercado seja permitido o lucro e não existam limites para este, só serão permitidos se dentro da prestação 
do serviço ou da atividade empresarial, valores mínimos forem respeitados. Se a busca pelo lucro ignora tais preceitos, poderá ser considerada inconstitucional e, portanto, proibida.

No Brasil, os valores também são ligados aos demais princípios e proteções individuais, sendo necessária uma análise sistemática da constituição para a apreensão específica da ordem econômica. Assim, no mesmo art. 170 em que a propriedade privada aparece como um valor a ser considerado, também a função social da propriedade está presente, o que traz o caráter social da economia no país. Demais valores apontados pela ordem brasileira remetem ao seu compromisso com o ser humano e a coletividade, valores que comparte, em grande medida, com a Espanha.

Estes valores, brasileiros e espanhóis, são frutos da busca pelo interesse público, que deverá estar acima daqueles que são considerados particulares, ou seja, interesses que são de proveito para o cidadão individualmente. Desta forma, defende-se que o interesse social é mais benéfico, uma vez que o ganho é coletivo e, portanto, visualiza-se a dignidade de cada ser em sua particularidade, o que pode ter como consequência, se for necessário, a redução do ganho do mercado privado. A questão cerne hoje, no entanto, compele ao questionamento acerca dos atuais modelos de Estado utilizados, principalmente quanto ao denominado Estado Garantidor/Regulador.

Este modelo de relação estatal com a economia determina que ao Estado cabe apenas a função de regulação e fiscalização das atividades econômicas praticadas pelo mercado, devendo abster-se ao máximo de atuar efetivamente como empresa. É uma reforma bastante contraditória, pois ao mesmo tempo em que deve garantir o interesse público, também tem a obrigação de auxiliar a iniciativa privada, ativando a economia, se necessário.

Apesar de todas as construções teóricas, no entanto, o que se tem na realidade brasileira é bastante diverso. Apesar dos princípios constitucionais de proteção do interesse público e auxílio à iniciativa privada, na prática tem-se, com frequência, o total abandono de questões socialmente relevantes, como privatizações de empresas públicas de serviço essencial (fornecedores de água, luz, saneamento, bancos, etc), entregando tais responsabilidades a agentes privados, e, ao mesmo tempo, políticas públicas que não auxiliam efetivamente aqueles que necessitam de apoio governamental, como é o caso de pequenas empresas e empresários individuais, que trabalham muitas vezes apenas com o intuito de "empatar" seus gastos e lucros. 
O que se tem no Brasil, e isto fica claro por meio de uma simples visualização da realidade, é um Estado que falha tanto na proteção do interesse público como no incentivo a economia, gerando insatisfação e o sentimento geral de ineficiência. O crescimento de grupos que defendem a "volta" do estado mínimo, em muito se justifica por estas discrepâncias existentes entre os objetivos constitucionalmente elencados e os que se visualizam na prática.

Assim, embora teoricamente o Estado Garantidor pareça a solução para uma convivência pacífica e agregadora entre interesse público e interesse privado, infelizmente suas melhores qualidades não se confirmam na prática, sendo que o poder segue sendo mantido nas mãos daqueles que sempre o tiveram e dele não abrem mão: os detentores do capital, e, consequentemente, do poder econômico.

\section{REFERÊNCIAS}

ABRANCHES, Sérgio Henrique. A questão da empresa estatal: economia, política e interesse público. Revista de administração de empresas. v. 19, (4), p. 95-105. out./dez 1979.

ARAUJO, Luiz Ernani Bonesso de. O Acesso a Terra no Estado Democrático de Direito. Frederico Westphalen: URI, 1997.

AVELÃS NUNES, Antônio José. Breve reflexão sobre o chamado estado regulador. Revista Seqüência, $n^{\circ}$ 54, p. 9-18, jul. 2007.

BARBOSA, Mafalda Miranda. A recusa de conformação do jurídico pelo econômico: breves considerações a propósito da responsabilidade civil. Boletim de ciências e econômicas. CUNHA, Luís Pedro; QUELHAS, José Manuel; ALMEIDA, Teresa. (org.) v. LVII, t. 1, p. 1115-1144, 2014.

BRASIL. Constituição da República Federativa do Brasil de 1988. Disponível em: <http://www.planalto.gov.br/ccivil_03/constituicao/constituicaocompilado.htm>. Acesso em: 11 abr. 2020.

BRASIL. Supremo Tribunal Federal. Ação Direta de Inconstitucionalidade $\mathbf{n}^{\mathbf{0}}$ 319. Relator: Min. Moreira Alves. Data de julgamento: 03/03/1993. Data de publicação DJ: 30/04/1993.

CAMARGO, Ricardo Antonio Lucas. Economia Política para o curso de Direito. Porto Alegre: Sergio Antonio Fabris, 2012.

CANOTILHO, J. José Gomes. O Estado Garantidor. In: AVELÃS NUNES, Antônio José; MIRANDA COUTINHO, Jacinto Nelson. O direito e o futuro: o futuro do Direito. São Paulo: Almedina, 2008. 
COMPARATO, Fabio Konder. Poder Político e capitalismo. Boletim de ciências e econômicas. CUNHA, Luís Pedro; QUELHAS, José Manuel; ALMEIDA, Teresa. (org.) v. LVII, t. 1, p. 1115-1144, 2014.

DONÁRIO, Arlindo Alegre; SANTOS, Ricardo Borges dos. Keynes e o Keynesianismo: uma visão crítica. Lisboa: CARS, 2016. Disponível em: $<$ http://repositorio.ual.pt/bitstream/11144/3169/3/KEYNES\%20E\%20O\%20KEYNESIANIS MO.pdf>. Acesso em: 1 abr. 2020.

ECHEVARRÍA, Santiago Garcia. El orden econômico em la Constitucion. Madrid: Libre Empresa, 1978.

ESPAÑA. Constitución española de 1978. Disponível em:

<http://www.congreso.es/consti/constitucion/indice/index.htm>. Acesso em: 02 abr. 2020.

ESPAÑA. Superior Tribunal Constitucional. Sentencia 1/1982, de 28 de janeiro (Pleno). Disponível em: <http://www.congreso.es/constitucion/ficheros/sentencias/stc_001_1982.pdf>. Acesso em: 02 abr. 2020.

FERNÁNDEZ-SANTA CRUZ, Monica Moreno. Constitución española de 1978: Sinopsis artículo 128. Dez. 2003. Disponível em:

<http://www.congreso.es/consti/constitucion/indice/sinopsis /sinopsis.jsp?art=128\&tipo=2>. Acesso em: 02 abr. 2020.

GARCIA, Elisenda Malareti. Regulación económica: su instrumentación normativa (El lugar de la ley en el Estado regulador, la experiencia reciente española). Derecho Privado y Constitución. Núm. 17. Enero-Diciembre, 2003.

GRAU, Eros Roberto. A ordem econômica na Constituição de 1988. 14 ed. rev. e at. São Paulo: Malheiros, 2010.

PÉREZ LUÑO, Antonio Enrique. Teoria del Derecho: una Concepcion de la Experiencia Juridica. 13 $3^{\mathrm{a}}$ ed. Madrid: Technos, 2014.

SMITH, Adam. Teoria dos Sentimentos Morais. São Paulo: Martins Fontes, 1999.

SOARES, Mário Lúcio Quintão. Teoria do Estado: novos paradigmas em face da globalização. 3 ed. São Paulo: Atlas, 2008.

STRECK, Lenio Luiz; MORAIS, José Luis Bolzan de. Ciência Política e Teoria Geral do Estado. 5 ed. Porto Alegre: Livraria do Advogado, 2006. p. 62

VAZ, Manuel Afonso. Direito Económico, 4. ${ }^{\text {a }}$ ed., Coimbra Editora, 1998. 